\title{
FORUM
}

\section{Plant Volatiles: New Perspectives for Research in Brazil}

\author{
Alberto Arab and José M.S. Bento \\ Depto. Entomologia, Fitopatologia e Zoologia Agrícola. Escola Superior de Agricultura "Luiz de Queiroz" (Esalq) \\ USP. Av. Pádua Dias 11, C. postal 9, 13418-900 Piracicaba, SP, alberto@esalq.usp.br
}

Neotropical Entomology 35(2):151-158 (2006)

Voláteis de Plantas: Novas Perspectivas de Pesquisa no Brasil

\begin{abstract}
RESUMO - Os agroecossistemas consistem em complexas relações tróficas entre plantas hospedeiras, herbívoros e seus inimigos naturais. Este trabalho revisa as pesquisas com voláteis de plantas no Brasil, apresenta os múltiplos mecanismos de resistência em culturas de importância econômica e contribui para o conhecimento das defesas induzidas em plantas. Uma grande parte dos programas de manejo de pragas, incluindo controle químico e biológico, não considera o impacto dessas substâncias sobre herbívoros e seus inimigos naturais. Estratégias alternativas de controle estão sendo desenvolvidas para o entendimento dos mecanismos endógenos de defesas induzidas em plantas contra artrópodes fitófagos. A utilização de voláteis de plantas no manejo integrado de pragas é uma estratégia adicional e ecologicamente sustentável no controle de pragas. Essa técnica envolve a possibilidade de utilização de iscas como atraentes de organismos benéficos, e a manipulação dos processos bioquímicos que induzem e regulam as defesas em plantas. A determinação dos mecanismos responsáves pela defesa indireta de plantas resultará em avanços significativos no controle biológico de pragas.
\end{abstract}

PALAVRAS-CHAVE: Defesa indireta, resposta induzida, sistema tritrófico, controle de pragas

\begin{abstract}
Agroecosystems consist on complex trophic relationships among host plants, herbivores and their natural enemies. This article reviews the research of plant volatiles in Brazil, in order to determine multiple resistance mechanisms of economically important crops and to contribute to the understanding of insect-plant interactions. Most pest management programs, including chemical and biological control, do not consider the impact of these chemicals on herbivores and their natural enemies. Alternative control methods are being developed in order to improve our understanding on the endogenous mechanisms of plant induced defenses against phytophagous arthropods. The use of plant volatiles technology as an additional tool in integrated pest management programs would offer a new and environmentally sound approach to crop protection. This technique involves the development of baits that attract beneficial organisms and the manipulation of biochemical processes that induce and regulate plant defenses, key factors in the improvement of control programs against economically important pests. The elucidation of the mechanisms involved in the indirect defenses of plants will result in useful tools for biological control of crop pests.
\end{abstract}

KEY WORDS: Indirect defense, induced response, tritrophic system, pest control

Although herbivores that forage for suitable food items often use volatiles emitted by healthy plants as cues (Dicke \& van Loon 2000, Pickett et al. 2003), plants also respond to the damage caused by phytophagous arthropods through the regulation of biochemical pathways that induce the release of chemical compounds, which will either repel herbivores or attract natural enemies (predators or parasitoids) of these organisms (Karban \& Baldwin 1997, Dicke 2000, Halitschke et al. 2000, Fraser et al. 2003, Heil 2004b).

Plant volatiles are derivated from complex biochemical processes and some of these compounds appear to be common to different plant species. However, there are also compounds that are species-specific and are elicited by herbivore-specific cues (Halitschke et al. 2001). Plant volatiles include sixcabon alcohols, monoterpenes, sesquiterpenes, and compounds derivated from the shikimic acid pathway (Turlings et al. 1998, Ferry et al. 2004). The existence of significant genotypic differences in the emission pattern of these compounds for some plants has been demonstrated (Gohole et al. 2003b) and it has been suggested that the release of these compounds may vary along the day, in a 
circadian manner (Benrey et al. 1998, Halitschke et al. 2000). Moreover, the induced release of volatiles is not limited to the site of damage but can occur systemically (Potting et al. 1995).

Herbivore feeding and mechanical damage can induce responses in plants that may be either systemic or restricted to the wound site. Wound-induced responses in plants are largelly mediated by molecules of the octadecanoid pathway (jasmonic acid, methyl jasmonate, and 12-oxophytodienoic acid). The production of plant volatiles can also be induced by exogenous application of jasmonic acid or methyl jasmonate, resulting in effects similar to plant responses induced by herbivores (Dicke \& van Loon 2000, Gols et al. 2003). In addition, any compound originated from the herbivore that interacts with the plant on a cellular level is a potencial elicitor. Herbivore specific elicitors have been isolated from both oral secretions and oviposition fluids of some insects. These isolated elicitors correspond to lytic enzymes, fatty acid-amino acid conjugates (FACs), long chains diols that are mono- and diesterified with 3-hydroxypropanoic acid, and by ion-channel forming peptides from fungi (Alborn et al. 2000, 2003; Engelberth 2000; Kessler \& Baldwin 2002b; Hoballah et al. 2004).

The ecological role of induced or non-induced plant volatiles may also differ among plant and herbivore species; thus, plant volatiles may act as a direct defense by hampering oviposition and damage from herbivores but they may also attract herbivores and thereby incur in ecological costs (Heil 2004a). Plant volatiles may also affect the release of these compounds by adjacent plants (Dicke \& van Loon 2000, Kessler \& Baldwin 2004). The previous exposure of plants to volatiles from herbivore infested neighbours results in a stronger response in terms of natural enemy attraction when herbivores damage the plant (Choh et al. 2004).

Volatile blends released by plants can be specific for some plant-herbivore interactions (Dicke \& van Loon 2000) and factors as plant species, leaf age, plant tissue, and herbivore species, may affect the volatile blend composition (De Moraes et al. 1998). Top-down control of herbivore populations is achieved by attracting predators and parasitoids to the feeding herbivore mediated by the production of these volatile compounds (Ferry et al. 2004).

\section{Trophic Effects of Plant Volatiles}

Natural ecosystems consist of complex trophic interactions between plant, herbivores, and natural enemies (Fig. 1). A number of plant species provide food (extrafloral nectar and pollen) and shelter (specialized plant structures) for the enemies of herbivores, thus facilitating the action of these organisms. Moreover, it has been well established that plants under herbivore attack are the source of chemical cues enabling orientation by both carnivores (Dicke \& van Loon 2000) and herbivores, thus indicating that these signals are important for distant host location by arthropods.

Widely studied trophic interactions include plant-spider mite-predatory mite, plant-leaf beetle-egg parasitoid, plantcaterpillar-parasitoid, and plant-caterpillar-predatory bug. The predatory mite Phytoseiulus persimilis Athias-Henriot
(Acari: Phytoseiidae) is a specialist enemy of the polyphagous spider mite Tetranychus urticae Koch (Acari: Tetranychidae). P. persimilis can use plant volatiles released by lima bean plants Phaseolus lunatus L. (Fabaceae) infested with $T$. urticae to locate its prey. In this tritrophic system, the volatile compound methyl jasmonate and some terpenoids determine the preference of $P$. persimilis; however, some plant species infested with spider mites do not produce methyl jasmonate, suggesting that other compounds can be also act as cues for the predatory mite (Dicke et al. 2003, Gols et al. 2003, Boer et al. 2004b). Moreover, $P$. persimilis shows a flexible behavioral response to different volatile blends that can be regulated by the previous experience of the mite to specific compounds released by the plants (Dicke et al. 2000, Boer et al. 2004a).

Plant volatiles can also be induced as a result of oviposition by herbivores, and these compounds may attract egg parasitoids. To date, oviposition-induced volatiles have been reported for three systems including a leaf beetle, a sawfly, and a stinkbug as herbivores and three different parasitic wasps. Indeed, there is evidence that plants can emit more volatiles when feeding activity is combined with oviposition on leaf surfaces, indicating the presence of a synergistic effect between the egg masses/oviduct secretion and the tissue damage caused by the herbivore (Meiners \& Hilker 2000, Hilker et al. 2002, Colazza et al. 2004b). Volatiles are released by the elm Ulmus minor Miller (Ulmaceae) induced by both oviposition and damage by the leaf beetle Xanthogaleruca luteola Müller (Coleoptera: Chrysomelidae). These compounds attract the egg parasitoid Oomyzus gallerucae Fonscolombe (Hymenoptera: Chalcididae). Furthermore, behavioral bioassays showed that odors from feces and eggs of the leaf beetle are attractive to O. gallerucae, suggesting that other compounds (kairomones) may be also be used by the parasitoid for short range host recognition (Meiners \& Hilker 1997, 2000).

Stemborer parasitoids are also attracted to volatiles emanating from gramineous plants, which are the main host plants for their herbivore hosts (Potting et al. 1995). Volatiles released by maize and sorghum plants infested with Busseola fusca Fuller (Lepidoptera: Noctuidae) or Chilo partellus Swinhoe (Lepidoptera: Crambidae) are potent attractors of the parasitoids Cotesia sesamiae Cameron, C. flavipes Cameron (Hymenoptera: Braconidae) and Dentichasmias busseolae Heinrich (Hymenoptera: Ichneumonidae). Additionally, C. sesamiae and D. busseolae showed preference for volatiles emitted by sorghum in relation to maize plants, thus suggesting a genetic adaptation of these parasitoids for searching on sorghum, a plant with which it shares a longer evolutionary history (Ngi-Song et al. 2000, Gohole et al. 2003a,b). The parasitoid Apanteles subandinus Blanchard (Hymenoptera: Braconidae) is attracted to plant foliage infested with the potato tuber moth Phthorimaea opercullela Zeller (Lepidoptera: Gelechiidae). Females of A. subandinus discriminate between volatiles of a mechanically damaged plants and those of damaged by $P$. opercullela, suggesting that volatile compounds emitted from host plant sources alone are inefficient cues for the attraction of the parasitoid (Salehi \& Keller 2002). 


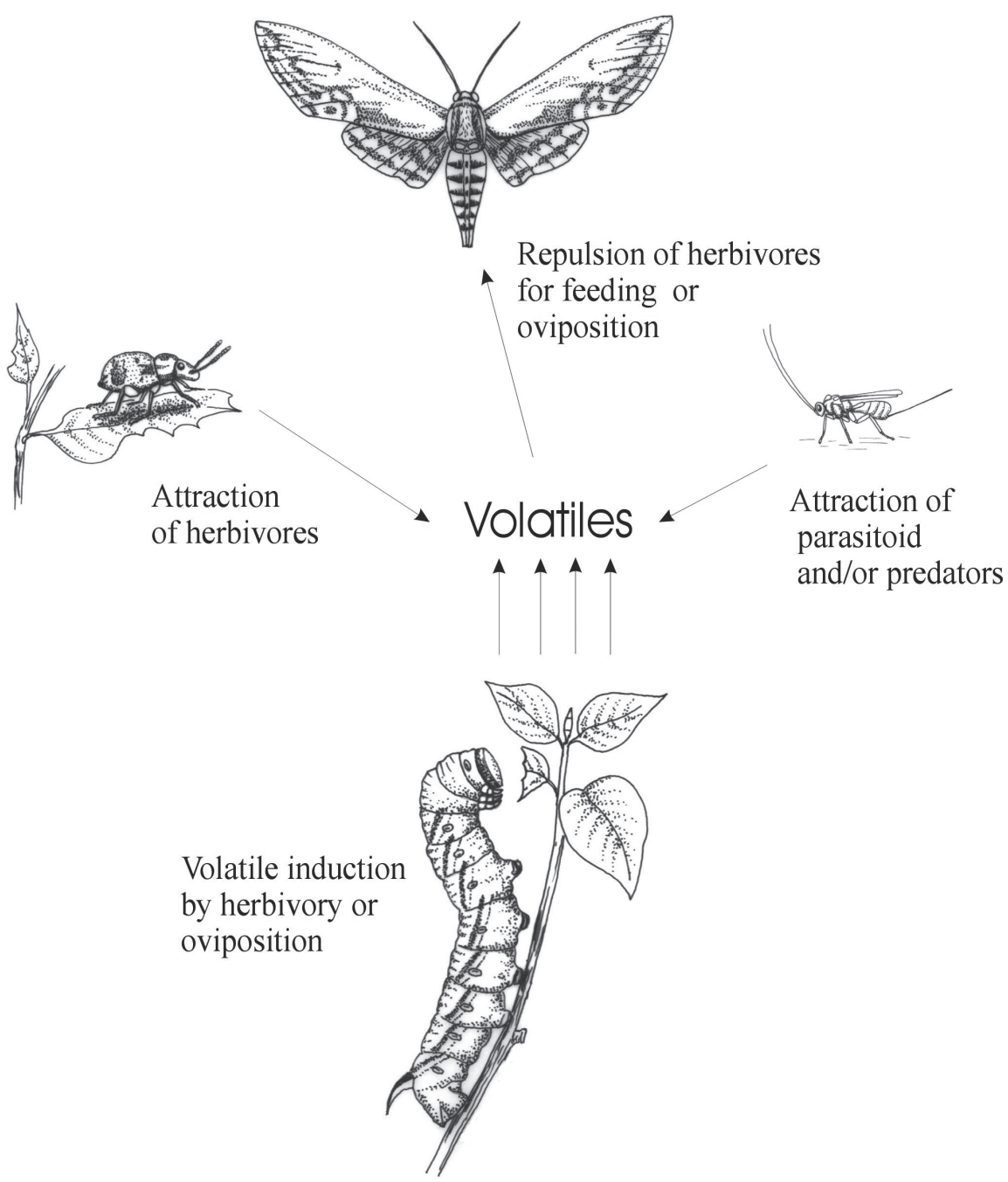

Fig. 1. Trophic interactions among host plants, herbivores, and predators or parasitoids mediated by plant volatiles.

Another naturally occurring tritrophic system involves the tobacco plant Nicotiana attenuata Torrey (Solanaceae), the tobacco hornworm Manduca sexta L. (Lepidoptera: Sphingidae), and the predatory bug Geocoris pallens Stal (Hemiptera: Geocoridae), which is attracted by volatiles of $N$. attenuata under the attack of phytophagous arthropods (Baldwin 2001). Moreover, tobacco plant volatiles released after the attack of the bug, Tupiocoris notatus Distant (Hemiptera: Miridae) also result in a similar attraction of the generalist predator G. pallens, although it showed preference by non-mobile preys like eggs and early instars of M. sexta (Kessler \& Baldwin 2004). Less information is available concerning tritrophic systems comprised of host plants, herbivores with stylet-feeding habits, and their parasitoids. These feeding habits have a different effect on plant tissues and, as a result, plant responses may be somewhat different than when attacked by other herbivores (Bernasconi et al. 1998, Birkett et al. 2003, Park \& Hardie 2003, Colazza et al. 2004a). Moraes et al (2005) showed that the egg parasitoid Telenomus podisi Ashmead (Hymenoptera: Scelionidae), is attracted to Glycine max L. and Cajanus cajan L. (Fabaceae) plants attacked by Euchistus heros (Hemiptera: Pentatomidae); however, the emission of plant volatiles under the attack of a non-host species of $T$. podisi were not attractive to the parasitoid, suggesting that induced volatile blend by the saliva of $E$. heros is different to those induced by a chewing insect.

Behavioral evidence suggests that carnivores are capable to differentiate among various blends at sites saturated with these compounds (Takabayashi \& Dicke 1996, Dicke \& van Loon 2000). Different methods have been developed to determine host specific mechanisms induced by plant volatiles on natural enemies ( Degenhardt et al. 2003, Gols et al. 2003) and some studies have been carried out, either using electrophysiological analysis or synthetic mimics of natural blends, in order to determine whether carnivore arthropods can choose a specific volatile mixture. This knowledge is essential to discern which major biosynthetic routes lead to the production of the plant volatiles that attract these organisms; however, not all herbivore-induced compounds have been identified to date.

Some herbivorous arthropods can use volatiles as a cue 
to detect host plants (Zhang et al. 1999, Kessler \& Baldwin 2001, Baldwin 2001); however, this information has proved misleading. Females of the potato tuber moth P. operculella are strongly attracted to volatiles of damaged Lycopersicum hirsutum and Solanum tuberosum L. (Solanaceae) plants over those from healthy ones (Fig. 2). Similarly, the Colorado potato beetle Leptinotarsa decemlineata Say (Coleoptera: Chrysomelidae) is attracted to damaged S. tuberosum plants (Dickens 2002). Some natural host plants are attractive to crop pests of great economic importance. Males of Bucephalogonia xanthophis (Berg) (Hemiptera: Cicadellidae) are attracted to plant volatiles released by leaves of Vernonia condensata Beker (Asteraceae) (Table 1), which occurs naturally in citrus cultivars (Bento et al., unpublished). Furthermore, volatile compounds released by glandular trichomes of Cordia curassavica Jaq. R.\&S (Boraginaceae) are strongly attractant to the weevil Cratosomus flavofasciatus Guerin (Coleoptera: Curculionidae), which is also an important pest of some Brazilian fruit cultivars, including citrus species (Bento et al., unpublished). Avoidance of plant volatiles has also been described for some insect-plant interactions (De Moraes et al. 2001, Heil 2004c), and there is evidence that the response of insects is correlated with their sex or physiological state (Fig. 3); time after volatile induction (Fig. 3); or the circadian rhythms of plants and insects (De Moraes et al. 2001). It is possible that volatile compounds indicate whether the plant is suitable for feeding and larval development, as demonstrated for fecundated females of P. operculella in potato plants (Arab \& Bento, unpublished), or for mating aggregation. However, the advantages that translate into increased fitness to herbivores that avoid host plants might be adaptative to these insects since it could reduce intraspecific competition and predation or even act as a signal indicating that direct defenses of the plants can been readily activated. Consequently, for herbivores plant volatiles represent a complex message that is interpreted according to their biological context.

Plant volatiles can also influence sex pheromone communication by enhancing both pheromone production and response (Landolt \& Phillips 1997). The effect of the sex pheromone of Cydia pomonella L. (Lepidoptera: Tortricidae) on males is greatly enhanced by volatiles released by the host plants, thus increasing communication distances by amplifying weak pheromone signals (Yang et al. 2004). Moreover, the synergism between host plant volatiles and sex pheromones also plays an important role in reproductive isolation, as demonstrated for some lepidopteran species (Witzgall et al. 1991).

It has been assumed that indirect defenses can only be maintained over evolutionary time if the plants benefit from induction (Hoballah et al. 2004). In order to increase plant fitness, herbivore-induced plant volatiles should be specific to predators or parasitoids, aiding in the effective localization of its prey and thus reducing the herbivore population, even in the presence of direct plant defenses that may act directly or indirectly on carnivores. Additionally, the positive fitness effect of attracting carnivores must be greater than the costs of attracting additional herbivores (Kessler \& Baldwin 2002a). Laboratory studies have demonstrated for some trophic systems that plants benefit from attracting parasitoids. Parasitization of Pieris rapae L. (Lepidoptera: Pieridae) by Cotesia rubecula Marshall (Hymenoptera: Braconidae) conferred a considerable fitness benefit for Arabidopsis thaliana L. (Brassicaceae) plants when compared to plants exposed to feeding damage by unparasitized $P$. rapae larvae (Loon-Joop et al. 2000). The potential fitness benefit of tobacco plants was also increased by the activity of plant volatiles on the generalist predator G. pallens, since this predator attacks early instar of $M$. sexta larvae (Kessler \& Baldwin 2002a). Moreover, injured tobacco plants that did not suffer herbivore attack showed a reduced production of seeds when compared to induced plants that were attacked by the tobacco hornworm larvae

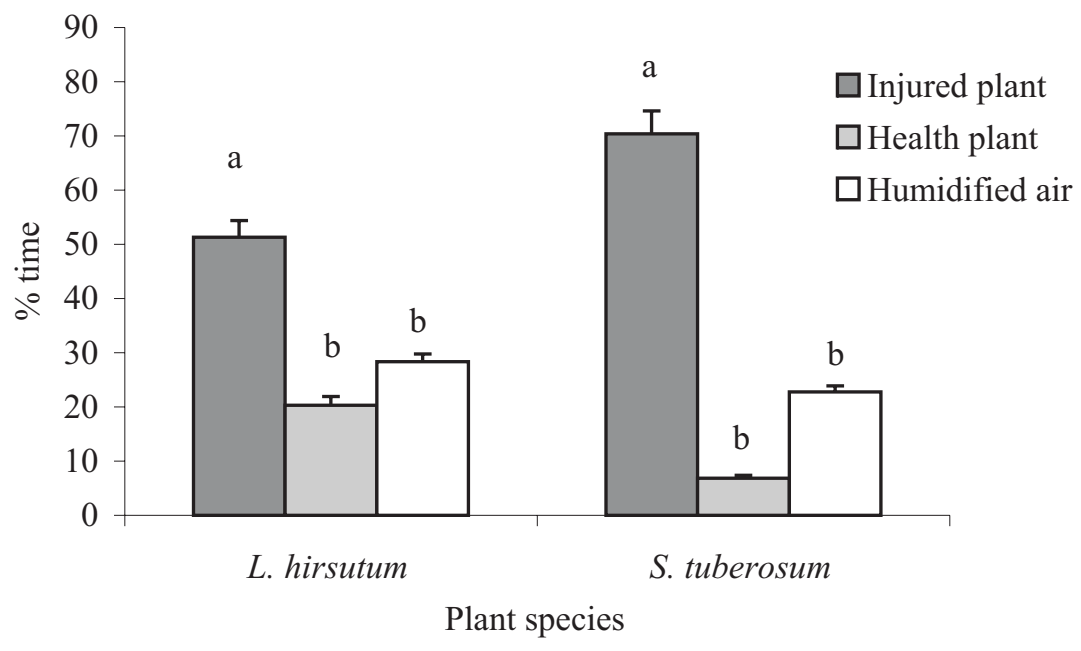

Fig. 2. Response (mean \% time spent/field) of fecundated females of Phthorimaea operculella to volatiles released from different host plant species in a four-arm olfactometer. Different letters indicate significant differences among treatments (Kruskal-Wallis test, $\mathrm{P}<0.05$ ). 
Table 1. Response of males of B. xanthophis to volatiles from leaves of $V$. condensata in a four-arm olfactometer.

\begin{tabular}{lcccc} 
& \multicolumn{3}{c}{ Odour field } \\
\cline { 2 - 5 } Response & Hexane & Fresh leaves & Leaves extract & Air \\
\hline No. choice $^{*}$ & $3 \mathrm{a}$ & $11 \mathrm{~b}$ & $4 \mathrm{a}$ & $2 \mathrm{a}$ \\
${\text { Mean } \% \text { time spent/field }(\%)^{* *}}^{n}$ & $16.68 \mathrm{a}$ & $46.51 \mathrm{~b}$ & $29.72 \mathrm{~b}$ & $7.10 \mathrm{a}$ \\
\hline
\end{tabular}

Different letters in the same row indicate significant differences among treatments (Chi-square ${ }^{*}$ test and Kruskal-Wallis test* ${ }^{*}$, $\mathrm{P}<0.05)$.

(Baldwin 2001). These results suggest that the costs of induced volatile production are compensated only in environments where natural enemies are present (Hoballah et al. 2004); however, fitness benefits for the plants are not the rule and, in some cases, parasitized larvae consume more plant material than unparasitized larvae. Therefore, plant fitness relies on the type of carnivore arthropod that responds to the information provided by the volatiles (Kessler \& Baldwin 2002a).

\section{Perspectives for Plant Volatile Research in Brazil}

With a projected increase in world population, an immediate priority for agriculture is to achieve maximum production in a manner that is environmentally sustainable and cost-effective. Brazilian economy relies on agricultural products; however, at present there are no research groups focusing on the potential exploitation of insect-plant interactions of crops in future biocontrol strategies. Clearly, losses due to insect herbivores significantly limit crop production and consideration of insect pest-host plant interaction is essential for agricultural application of biocontrol measures. Research on plant volatiles may come to help to reduce the impact of insecticides on Brazilian ecosystems and to decrease crop production costs, thus improving the overall socio-economical conditions of the region.
As knowledge on the tritrophic interactions increases, one of the major challenges in Brazil is how to exploit plant volatile information to develop novel strategies for pest control. The possibility of using plant volatiles for the manipulation of parasitoids appears to be a powerful tool for the control of regional pest crops, as demonstrated by the results obtained in experiments using the parasitoids $T$. podisi in soybean (Moraes et al. 2005) and Tamarixia radiata (Waterston) (Hymenoptera: Eulophidae) in citrus (Arab et al., unpublished). On the other hand, manipulating the release of plant volatiles can be useful to minimize pest problems in agriculture. In the case of some volatile compounds, genetic engineering or conventional breeding could be employed to manipulate the synthesis of these compounds, given that some plant varieties are known to differ in the amount and composition of the volatiles they produce (Kessler \& Baldwin 2002a, Degenhardt et al. 2003). Additionally, in order to improve manipulation techniques it is recommended to select model plants that exhibit a large amount of morphological and chemical phenotypic plasticity and short life cycles. By using genetic engineering it is possible to introduce the emission of some volatile compounds into crops that do not have this trait or increase the flux of these compounds, thus resulting in a stronger signal that attracts natural enemies (Kappers et al. 2005) or repels herbivores. Furthermore, the blend composition could be manipulated to match the preference of a particular

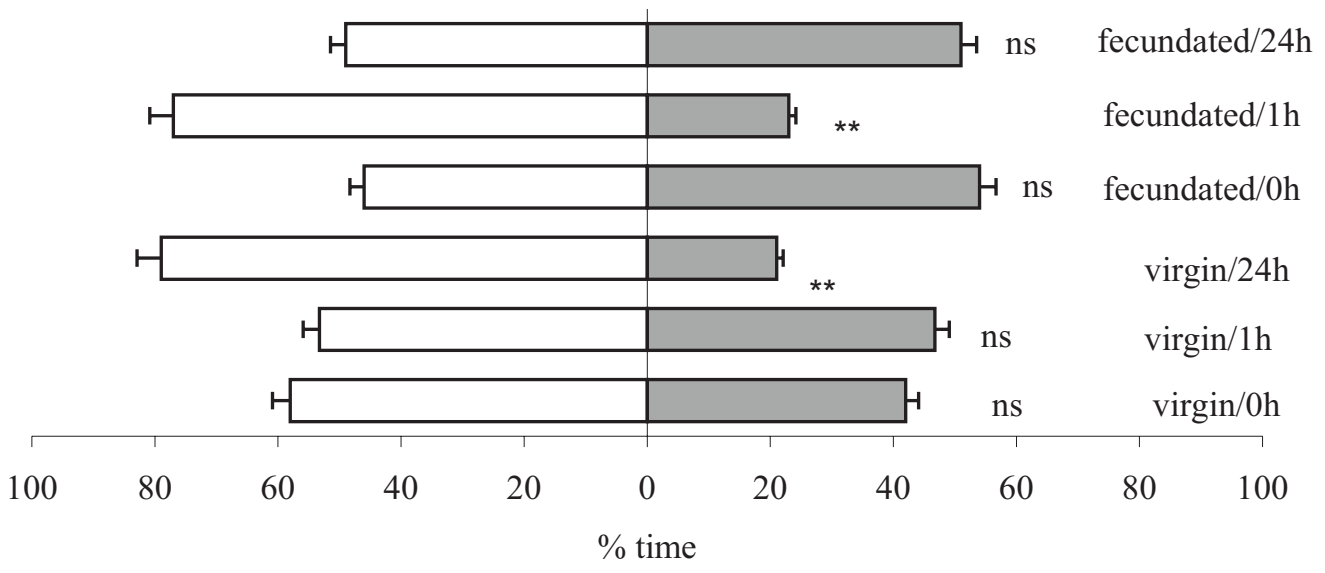

Fig. 3. Response (mean \% time spent/field) of females of P. operculella to volatiles released from L. esculentum cv Paron in a four-arm olfactometer.

** indicates significant differences between injured (filled bars) and humidified air (open bars); ns indicates no significant differences (Kruskal-Wallis test, $\mathrm{P}<0.05$ ). 
predator or parasitoid. This could be achieved by testing the preference of a potential carnivore to particular blends of induced plant volatiles through behavioral bioassays. On the other hand, for crops in which engineering of volatile emission is contemplated, it is important to avoid the attraction of more herbivores in response to the volatiles (Degenhardt et al. 2003).

Brazil has the great advantage of holding one of the richest flora diversity in the world, and this issue is particularly important when approaching strategies of plant volatile exploitation through the diversification of the agroecosystems by using naturally wild occurring plants within the crops. Until now, the results obtained from behavioral experiments with $C$. curassavica and $V$. condensata, open new perspectives for the introduction of intercrops and trap crops technologies, thus providing valuable control of important crop pests, which will contribute to the farmer's economies in the region. Agroecosystems consist on complex trophic relationships between host plants, herbivores, and their natural enemies, which are relevant for the use of plant volatiles knowledge as a tool for biological control and integrated pest management programs. Field evaluations of plant volatiles have been performed just in a few trophic systems and the results suggest that some synthetic blends are attractive to certain insects (James 2003a,b); however, the number of individuals captured in sticky traps impregnated with synthetic volatiles was relatively low. The exploitation of plant volatiles as attractants for beneficial arthropods in crop systems may require slow-release dispensation of synthetic volatiles over the crop area. Retention of natural enemies within the crop could also be influenced by synthetic plant volatiles and by the presence of the pest or the naturally occurring plant volatiles. In order to improve control methods using plant volatiles it will be important to understand these trophic interactions with the purpose of gain insight into the foraging behavior of natural enemies (Agrawal 2005) before recommending a habitat management strategy.

\section{Acknowledgments}

We thank Johana Rincones for reviewing the grammar and syntax of the English text and Patricia Milano and Cristiane Mileo for elaborating the diagrams. We also thank two anonymous reviewers for valuable suggestions and comments of the manuscript. This work was supported by FAPESP (Fundação de Amparo à Pesquisa no Estado de São Paulo), grants number 04/12365-4 and 01/06587-6.

\section{References}

Agrawal, A.A. 2005. Future directions in the study of induced plant responses to herbivory. Entomol. Exp. Appl. 115: 97105.

Alborn, H.T., M.M. Brennan \& J.H. Tumlinson. 2003. Differential activity and degradation of plant volatile elicitors in regurgitant of tobacco hornworm (Manduca sexta) larvae. J. Chem. Ecol. 29: $1357-1372$.
Alborn, H.T., T.H. Jones, G.S. Stenhagen \& J.H. Tumlinson. 2000. Identification and synthesis of volicitin and related components from beet armyworm oral secretions. J. Chem. Ecol. 26: 203-220.

Baldwin, I.T. 2001. An ecologically motivated analysis of plantherbivore interactions in native tobacco. Plant Physiol. 127: 1449-1458.

Benrey, B., A. Callejas, L. Rios, K. Oyama \& R.F. Denno. 1998. The effects of domestication of Brassica and Phaseolus on the interaction between phytophagous insects and parasitoids. Biol. Control 11: 130-140.

Bernasconi, M.L., C.J. Turlings-Ted, L. Ambrosetti, P. Bassetti \& S. Dorn. 1998. Herbivore-induced emissions of maize volatiles repel the corn leaf aphid, Rhopalosiphum maidis. Entomol. Exp. Appl. 87: 133-142.

Birkett, M.A., K. Chamberlain, E. Guerrieri, J.A. Pickett, L.J. Wadhams \& T. Yasuda. 2003. Volatiles from whitefly-infested plants elicit a host-locating response in the parasitoid, Encarsia formosa. J. Chem. Ecol. 29: 1589-1600.

Boer, J.d., M. Dicke \& J.G. de Boer. 2004a. Experience with methyl salicylate affects behavioural responses of a predatory mite to blends of herbivore-induced plant volatiles. Entomol. Exp. Appl. 110: 181-189.

Boer, J.d., M. Dicke \& J.G. de Boer. 2004b. The role of methyl salicylate in prey searching behavior of the predatory mite Phytoseiulus persimilis. J. Chem. Ecol. 30: 255-271.

Choh, Y., T. Shimoda, R. Ozawa, M. Dicke \& J. Takabayashi. 2004. Exposure of lima bean leaves to volatiles from herbivoreinduced conspecific plants results in emission of carnivore attractants: Active or passive process? J. Chem. Ecol. 30: 13051317.

Colazza, S., A. Fucarino, E. Peri, G. Salerno, E. Conti \& F. Bin. 2004b. Insect oviposition induces volatile emission in herbaceous plants that attracts egg parasitoids. J. Exp. Biol. 207: 47-53.

Colazza, S., J.S. McElfresh \& J.G. Millar. 2004a. Identification of volatile synomones, induced by Nezara viridula feeding and oviposition on bean spp., that attract the egg parasitoid Trissolcus basalis. J. Chem. Ecol. 30: 945-964.

De Moraes, C.M., W.J. Lewis, P.W. Pare, H.T. Alborn \& J.H. Tumlinson. 1998. Herbivore-infested plants selectively attract parasitoids. Nature 393: 570-573.

De Moraes, C.M., M.C. Mescher \& J.H. Tumlinson. 2001. Caterpillar-induced nocturnal plant volatiles repel conspecific females. Nature 410: 577-580.

Degenhardt, J., J. Gershenzon, I.T. Baldwin \& A. Kessler. 2003. Attracting friends to feast on foes: Enginering terpene emission to make crop plants more attractive to herbivore enemies. Curr. Opin. Biotechnol. 14: 169-176.

Dicke, M. 2000. Chemical ecology of host-plant selection by herbivorous arthropods: A multitrophic perspective. Biochem. Syst. Ecol. 28: 601-617.

Dicke, M., C. Schutte \& H. Dijkman. 2000. Change in behavioral 
response to herbivore-induced plant volatiles in a predatory mite population. J. Chem. Ecol. 26: 1497-1514.

Dicke, M. \& J.J.A. van Loon. 2000. Multitrophic effects of herbivore-induced plant volatiles in an evolutionary context. Entomol. Exp. Appl. 97: 237-249.

Dicke, M., J.G. de Boer, M. Hofte \& M.C. Rocha-Granados. 2003. Mixed blends of herbivore-induced plant volatiles and foraging success of carnivorous arthropods. Oikos 101: 38-48.

Dickens, J.C. 2002. Behavioural responses of larvae of Colorado potato beetle, Leptinotarsa decemlineata (Coleoptera: Chrysomelidae), to host plant volatile blends attractive to adults. Agri. Forest Entomol. 4: 309-314.

Engelberth, J. 2000. Differential signalling and plant-volatile biosynthesis. Biochem. Syst. Ecol. 28: 871-872.

Ferry, N., M.G. Edwards, J.A. Gatehouse \& A.M.R. Gatehouse. 2004. Plant-insect interactions: Molecular approaches to insect resistance. Curr. Opin. Biotechnol. 15: 155-161.

Fraser, A.M., W.L. Mechaber \& J.G. Hildebrand. 2003. Electroantennographic and behavioral responses of the sphinx moth Manduca sexta to host plant headspace volatiles. J. Chem. Ecol. 29: 1813-1833.

Gohole, L.S., W.A. Overholt, Z.R. Khan, J.A. Pickett \& L.E. Vet. 2003b. Effects of molasses grass, Melinis minutiflora volatiles on the foraging behavior of the cereal stemborer parasitoid, Cotesia sesamiae. J. Chem. Ecol. 29: 731-745.

Gohole, L.S., W.A. Overholt, Z.R. Khan \& L.E.M. Vet. 2003a. Role of volatiles emitted by host and non-host plants in the foraging behaviour of Dentichasmias busseolae, a pupal parasitoid of the spotted stemborer Chilo partellus. Entomol. Exp. Appl. 107: 1-9.

Gols, R., M. Roosjen, H. Dijkman \& M. Dicke. 2003. Induction of direct and indirect plant responses by jasmonic acid, low spider mite densities, or a combination of jasmonic acid treatment and spider mite infestation. J. Chem. Ecol. 29: 26512666 .

Halitschke, R., U. Schittko, G. Pohnert, W. Boland \& I.T. Baldwin. 2001. Molecular interactions between the specialist herbivore Manduca sexta (Lepidoptera: Sphingidae) and its natural host Nicotiana attenuata. III. Fatty acid-amino acid conjugates in herbivore oral secretions are necessary and suficient for herbivore-specific plant responses. Plant Physiol. 125: 711-717.

Heil, M. 2004. Direct defense or ecological costs: Responses of herbivorous beetles to volatiles released by wild lima bean (Phaseolus lunatus). J. Chem. Ecol. 30: 1289-1295.

Hilker, M., C. Kobs, M. Varama \& K. Schrank. 2002. Insect egg deposition induces Pinus sylvestris to attract egg parasitoids. J. Exp. Biol. 205: 455-461.

Hoballah, M.E., T.G. Kollner, J. Degenhardt \& T.C.J. Turlings. 2004. Costs of induced volatile production in maize. Oikos 105: $168-180$.

James, D.G. 2003a. Synthetic herbivore-induced plant volatiles as field attractants for beneficial insects. Environ. Entomol. 32: 977-982.
James, D.G. 2003b. Field evaluation of herbivore-induced plant volatiles as attractants for beneficial insects: Methyl salicylate and the green lacewing, Chrysopa nigricornis. J. Chem. Ecol. 29: 1601-1609.

Kappers, I.F., A. Aharoni, T.W.J.M. van Herpen, L.L.P. Luckerhoff, M. Dicke \& H.J. Bouwmeester. 2005. Genetic engineering of terpenoid metabolism attracts, bodyguards to Arabidopsis. Science 309: 2070-2072.

Karban, R. \& I. T. Baldwin. 1997. (eds.) Induced responses to herbivory. Chicago \& London, The University of Chicago Press, 319p.

Kessler, A. \& I.T. Baldwin. 2001. Defensive function of herbivoreinduced plant volatile emissions in nature. Science 291: 21412144.

Kessler, A. \& I.T. Baldwin. 2002a. Plant-mediated tritrophic interactions and biological pest control. AgBiotechNet. 4: 16.

Kessler, A. \& I.T. Baldwin. 2002b. Plant responses to insect herbivory: The emerging molecular analysis. Annu. Rev. Plant Biol. 53: 299-328.

Kessler, A. \& I.T. Baldwin. 2004. Herbivore-induced plant vaccination. Part I. The orchestration of plant defenses in nature and their fitness consequences in the wild tobacco Nicotiana attenuata. Plant J. 38: 639-649.

Landolt, P.T. \& T.W. Phillips. 1997. Host plant influences on sex pheromone behavior of phytophagous insects. Annu. Rev. Entomol. 42: 371-391.

Loon-Joop, J.A., J.G. de Boer \& M. Dicke. 2000. Parasitoid-plant mutualism: Parasitoid attack of herbivore increases plant reproduction. Entomol. Exp. Appl. 97: 219-227.

Meiners, T. \& M. Hilker. 1997. Host location in Oomyzus gallerucae (Hymenoptera: Eulophidae), an egg parasitoid of the elm leaf beetle Xanthogaleruca luteola (Coleoptera: Chrysomelidae). Oecologia 112: 87-93.

Meiners, T. \& M. Hilker. 2000. Induction of plant synomones by oviposition of a phytophagous insect. J. Chem. Ecol. 26: 221232.

Ngi-Song, A.J., G.N. Njagi-Peter, B. Torto \& W.A. Overholt. 2000. Identification of behaviourally active components from maize volatiles for the stemborer parasitoid Cotesia flavipes Cameron (Hymenoptera: Braconidae). Insect Sci. Appl. 20: 181-189.

Park, K.C. \& J. Hardie. 2003. Electroantennogram responses of aphid nymphs to plant volatiles. Physiol. Entomol. 28: 215220.

Pickett, J.A., H.B. Rasmussen, C.M. Woodcock, W. Matthes \& J.A. Napier. 2003. Plant stress signalling: Understanding and exploiting plant-plant interactions. Biochem. Soc. Trans. 31: 123-127.

Potting, R.P.J., L.E.M. Vet \& M. Dicke. 1995. Host microhabitat location by stem-borer parasitoid Cotesia flavipes: The role of herbivore volatiles and locally and systemically induced plant volatiles. J. Chem. Ecol. 21: 525-539. 
Salehi, L. \& M.A. Keller. 2002. Investigation on host finding behavior of the two parasitoids of potato tuber moth in a flight tunnel. J. Agri. Sci. Tech. 4: 3-4.

Turlings, T.C.J., U.B. Lengwiler, M.L. Bernasconi \& D. Wechsler. 1998. Timing of induced volatile emissions in maize seedlings. Planta 207: 146-152.

Witzgall, P., M. Bengtsson, J.-P. chambon, E. Priesner, T. Wildbolz $\&$ H. Arn. 1991. Sex pheromones of Spilonota ocellana and Spilonota laricana. Entomol. Exp. Appl. 60: 219-223.
Yang, Z., M. Bengtsson, P. Witzgall \& Z.H. Yang. 2004. Host plant volatiles synergize response to sex pheromone in codling moth, Cydia pomonella. J. Chem. Ecol. 30: 619-629.

Zhang, A., C. Linn, Jr., S. Wright, R. Prokopy, W. Reissig \& W. Roelofs. 1999. Identification of a new blend of apple volatiles attractive to the apple maggot, Rhagoletis pomonella. J. Chem. Ecol. 25: 1221-1232.

Received 10/V/2005. 